\title{
Transplantation of Stem Cells Obtained From Murine Dental Pulp Improves Pancreatic Damage, Renal Function, and Painful Diabetic Neuropathy in Diabetic Type 1 Mouse Model
}

\author{
Elisalva Teixeira Guimarães, ${ }^{*} \dagger$ Gabriela da Silva Cruz, ${ }^{*}+$ Tiago Farias de Almeida,* \\ Bruno Solano de Freitas Souza, $\$$ Carla Martins Kaneto, \\ Washington Luis Conrado dos Santos, ${ }^{*}$ Ricardo Ribeiro-dos-Santos, $* \ddagger$ \\ Cristiane Flora Villarreal,*§ and Milena Botelho Pereira Soares* $*$ \\ *Centro de Pesquisas Gonçalo Moniz, FIOCRUZ, Bahia, Brazil \\ $\dagger$ Universidade do Estado da Bahia, Salvador, Bahia, Brazil \\ \$Centro de Biotecnologia e Terapia Celular, Hospital São Rafael, Salvador, Bahia, Brazil \\ §Universidade Federal da Bahia, Salvador, Bahia, Brazil
}

\begin{abstract}
Diabetes mellitus (DM) is one of the most common and serious chronic diseases in the world. Here, we investigated the effects of mouse dental pulp stem cell (mDPSC) transplantation in a streptozotocin (STZ)-induced diabetes type 1 model. C57BL/6 mice were treated intraperitoneally with $80 \mathrm{mg} / \mathrm{kg}$ of STZ and transplanted with $1 \times 10^{6} \mathrm{mDPSCs}$ or injected with saline, by an endovenous route, after diabetes onset. Blood and urine glucose levels were reduced in hyperglycemic mice treated with mDPSCs when compared to saline-treated controls. This correlated with an increase in pancreatic islets and insulin production 30 days after mDPSC therapy. Moreover, urea and proteinuria levels normalized after mDPSC transplantation in diabetic mice, indicating an improvement of renal function. This was confirmed by a histopathological analysis of kidney sections. We observed the loss of the epithelial brush border and proximal tubule dilatation only in salinetreated diabetic mice, which is indicative of acute renal lesion. STZ-induced thermal hyperalgesia was also reduced after cell therapy. Three days after transplantation, mDPSC-treated diabetic mice exhibited nociceptive thresholds similar to that of nondiabetic mice, an effect maintained throughout the 90-day evaluation period. Immunofluorescence analyses of the pancreas revealed the presence of $\mathrm{GFP}^{+}$cells in, or surrounding, pancreatic islets. Our results demonstrate that mDPSCs may contribute to pancreatic $\beta$-cell renewal, prevent renal damage in diabetic animals, and produce a powerful and long-lasting antinociceptive effect on behavioral neuropathic pain. Our results suggest stem cell therapy as an option for the control of diabetes complications such as intractable diabetic neuropathic pain.
\end{abstract}

Key words: Stem cells; Dental pulp; Streptozotocin (STZ); Neuropathic pain; Hyperglycemia

\section{INTRODUCTION}

Diabetes mellitus (DM) is one of the most common and serious chronic diseases in the world. While type 1 diabetes (DM1) is characterized by the destruction of the insulin-producing $\beta$-cells in the pancreas mediated by autoreactive T-cells, type 2 diabetes (DM2) is associated with peripheral resistance to insulin and impaired insulin secretion $(5,9,26,27)$. The excess of glucose is responsible for most of the complications of DM1, which include blindness, kidney failure, amputations, and heart disease. Neuropathy is a frequent microvascular complication of diabetes, with patients often suffering from severe pain that can be acute of onset or chronic with symptoms lasting for many years. Patients with diabetic neuropathy can exhibit a variety of aberrant sensations, including spontaneous pain, allodynia, hyperalgesia, and loss of stimulus-evoked sensation $(23,28,30)$.

All devastating complications of DM1 can be prevented by the normalization of blood glucose levels. Conventional treatment includes the dependence on daily injections of insulin and routine monitoring of blood glucose levels. Other therapies such as transplantation of pancreatic islets can be applied to treat this disease, but its widespread use is hampered by a shortage of donor organs or a recurrent attack by underlying autoimmunity against islets $(4,5,22)$. Moreover, there are

Received January 19, 2011; final acceptance October 8, 2012. Online prepub date: October 12, 2012.

Address correspondence to Milena Botelho Pereira Soares, Centro de Pesquisas Gonçalo Moniz. Rua Waldemar Falcão, 121 - Candeal - Salvador, BA, Brazil, 40296-710. Tel: +55-71-3176-2292, ext. 260/272; Fax: +55-71-3176-2272; E-mail: milena@bahia.fiocruz.br 
no treatments that restore nerve function and the usual therapeutic strategies for neuropathic pain aim to reduce the pain. Unfortunately, most of the available analgesic drugs appear to be relatively ineffective in controlling diabetic neuropathic pain $(14,18)$. Thus, there is a clear need for new disease-modifying therapeutic approaches. In this context, cell-based therapies represent a promising alternative. Several reports have suggested that embryonic or adult bone marrow stem cells contribute to $\beta$-cell renewal and possess great potential for damaged nervous system repair $(11,13,21,24,27)$. In fact, transplantation of bone marrow mononuclear cells significantly reduced the pain behavior following peripheral nerve injury and is a renewable alternative source of insulin-producing cells in human or mouse models $(12,16,19,29)$.

We have recently described the isolation, characterization, and differentiation of stem cells obtained from mouse dental pulp (mDPSCs) (10). We observed that mDPSCs are a population of stem cells with mesenchymal and embryonic characteristics, since they express mesenchymal cell surface molecules such as cluster of differentiation 90 (CD90), CD73, lymphocyte antigen 6 complex, locus A/stem cell antigen 1 (Ly6a/Sca-1), and the embryonic markers stage-specific embryonic antigen-1 (SSEA-1), POU [Pit-1-octamer-Unc-86] domain class 5 homeobox 1/octamer binding transcription factor 4 (Pou5f1/Oct-4), and alkaline phosphatase (10). This mesenchymal/embryonic mixed profile of stem cells obtained from human dental pulp has been previously described by other authors $(13,16)$. Moreover, mDPSCs also have differentiation potential in osteocytes, adipocytes, and chondrocytes (10). In the current study, we evaluated the therapeutic potential of mDPSCs in important complications of diabetes, namely pancreatic damage, renal function alterations, and diabetic peripheral neuropathy. For this, we studied the effects of mDPSCs on a model of pancreatic damage induced by streptozotocin (STZ), an antibiotic isolated from Streptomyces achromogenes widely used to create rodent models of type 1 diabetes (2).

\section{MATERIALS AND METHODS}

Mice

Specific-pathogen-free, 8-week-old female C57BL/6 and male $\mathrm{C} 57 \mathrm{BL} / 6$ enhanced green fluorescent protein (GFP) mice were maintained at the animal facilities at the Gonçalo Moniz Research Center-FIOCRUZ (Salvador, Bahia, Brazil) and provided with rodent diet and water ad libitum. Animals were used only once in a given experiment. All experiments were carried out in accordance with the recommendations of the International Association for the Study of Pain (IASP) Committee for Research and Ethical Issues Guidelines and were approved by the local Animal Ethics Committee.

\section{Isolation and Culture of mDPSCs}

The incisors teeth were dissected carefully from the mandibles of male EGFP transgenic C57BL/6 mice. Dental pulp tissue was gently collected, and explants were cultured into 24-well plates (Nunc A/S, Roskilde, Denmark) in Dulbecco's modified Eagle's medium (DMEM; Sigma, St. Louis, MO, USA) supplemented with $10 \%$ fetal bovine serum (FBS; Cultilab, Campinas, SP, Brazil), $23.8 \mathrm{mM}$ sodium bicarbonate (Sigma), $10 \mathrm{mM}$ 4-(2-hydroxyethyl)1-piperazineethanesulfonic acid (HEPES; Santa Cruz Biotechnology, Santa Cruz, CA, USA), $1 \mathrm{mM}$ sodium pyruvate (Sigma), $2 \mathrm{mM}$ L-glutamine (Sigma), $0.05 \mathrm{mM}$ $\beta$-mercaptoethanol (2-ME; Sigma), $50 \mu \mathrm{g} / \mathrm{ml}$ gentamycin (Sigma) and incubated at $37^{\circ} \mathrm{C} / 5 \% \mathrm{CO}_{2}$. When confluence was achieved usually after 15-20 days, the adherent cells were released with $0.25 \%$ trypsin solution (Invitrogen/ Molecular Probes, Eugene, OR, USA) and used to treat diabetic mice, as described below. Cells until the fifth passage were used for transplant.

\section{Streptozocin Injection and mDPSC Transplantation Model}

$\beta$-Cell injury was induced with streptozotocin (STZ) injection. Female C57BL/6 mice were injected intraperitoneally (IP) with $80 \mathrm{mg} / \mathrm{kg} \mathrm{STZ} \mathrm{(Sigma)} \mathrm{diluted} \mathrm{in}$ a citrate buffer ( $\mathrm{pH} 4.5$; Invitrogen, Carlsbad, CA, USA). Negative control group received vehicle (citrate buffer) only. Mice were considered diabetic if glucose levels were above $250 \mathrm{mg} / \mathrm{dl}$. About $70 \%$ of the animals developed hyperglycemia. After 10 days, hyperglycemic mice ( $n=6$ /group) were transplanted by orbital plexus injection with $1 \times 10^{6}$ cells/mouse in a final volume of $200 \mu \mathrm{l}$ of saline. Control group received saline only $(n=6 /$ group). Blood glucose levels were measured weekly with the glucometer system Accu-Chek (Roche Diagnostic, Mannheim, Germany). Animals were housed individually in metabolic cages for $24 \mathrm{~h}$. Urine was collected, and levels of proteinuria, glycosuria, urea, and creatinine were measured by standard biochemical kits (Biosystems, Barcelona, Spain). The experimental design is shown in Figure 1.

\section{Histopathological Evaluation}

Kidneys and pancreas were removed after 30 days of experiment and immediately placed in Bouin solution (Sigma) and formol (Proquímios, Bangu, Brazil), respectively. After $24 \mathrm{~h}$ of fixation, tissues were washed and embedded in paraffin, and 3- and 5-mm-thick sections were stained with conventional hematoxylin and eosin (H\&E; Vetec, Duque de Caxias, Brazil) or periodic acid-Schiff (PAS; Sigma) stainings. Glycogen deposition was visualized after PAS staining by light microscope (Olympus, Center Valley, PA, USA), and the number 


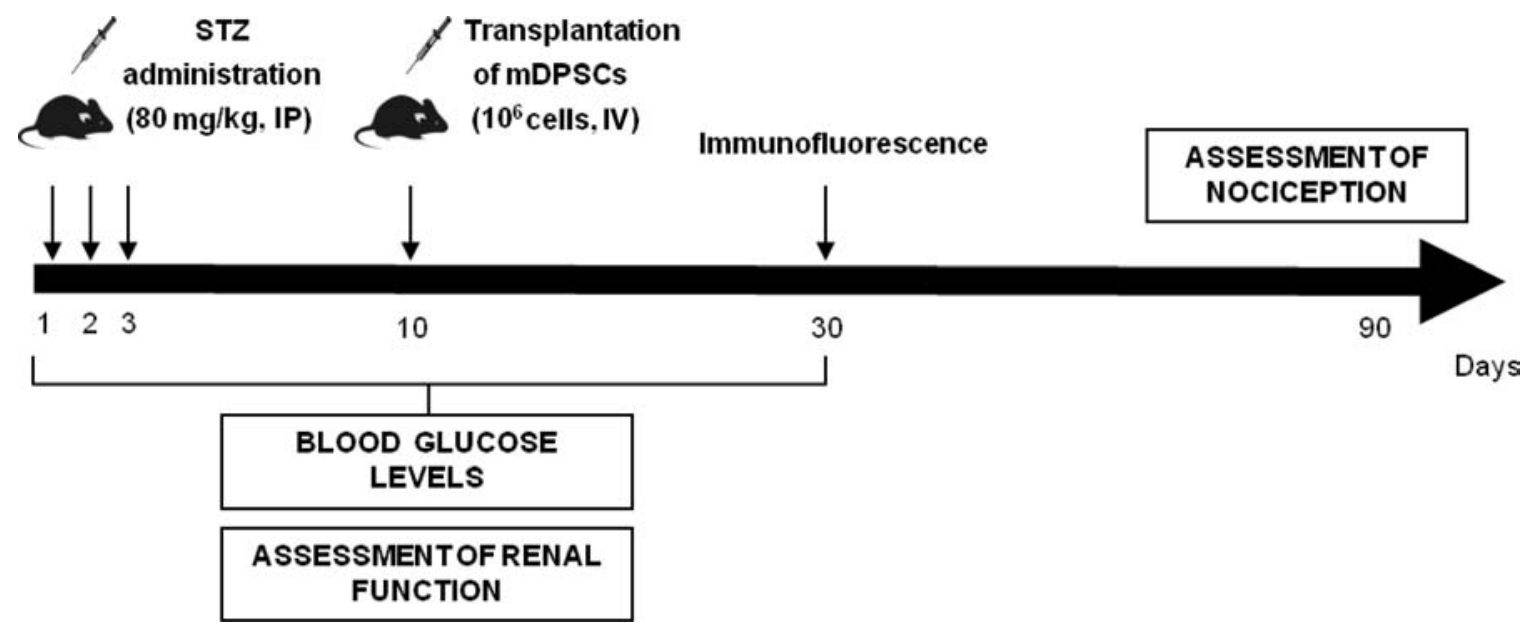

Figure 1. Experimental design. Diabetes was induced in mice by three daily administrations of streptozotocin (STZ) in identical concentrations. Control mice received three daily injections of citrate buffer. On day 10 following the STZ administrations, mice received injection of $10^{6}$ mouse dental pulp-derived stem cells (mDPSCs) or saline by endovenous route (through the orbital plexus).

of islets was determined by manual counting of whole pancreas sections stained with H\&E digitalized with ScanScope, a digital slide scanner (Aperio, Vista, CA, USA). A mean \pm SD area of $102.5 \pm 21.8 \mathrm{~mm}^{2}$ of pancreatic tissue was analyzed per mouse.

\section{Assessment of Nociception: Tail Flick Test}

The tail flick test of D'amour and Smith (6) modified for mice was used. The mice were habituated in a Plexiglas cylindrical mouse restrainer (Stoelting Research Instruments, Wood Dale, IL, USA) 10 min daily for 1 week before starting the experiments. To measure the latency of the tail flick response, mice were gently placed in the restrainer and the tails ( $2 \mathrm{~cm}$ from the tip) were immersed in a water bath maintained at $54.0 \pm 0.2^{\circ} \mathrm{C}$. The monitored response was a curling of the tail. A cutoff latency of $20 \mathrm{~s}$ was used to minimize the probability of skin damage. Baseline withdrawal latencies were obtained from mice before diabetes induction.

\section{Immunofluorescence Analysis}

The pancreas was removed from mice euthanized 30 days after the first STZ administration, fixed with $4 \%$ paraformaldehyde (Sigma), and embedded in paraffin. Pancreatic sections (4- $\mu \mathrm{m}$ thick) were obtained, deparaffinized, and submitted to a heat-induced antigen retrieval step in citrate buffer (pH 6.0; Vetec). Sections were then incubated overnight with primary antibodies guinea pig anti-insulin (Invitrogen) diluted 1:50 and chicken anti-GFP (Aves Biotech, Tigard, OR, USA) diluted 1:100. The next day, the sections were incubated with the secondary antibodies for $1 \mathrm{~h}$ at room temperature. The following secondary antibodies were used: goat anti-guinea pig $\operatorname{IgG}$ Alexa Fluor conjugated with Alexa Fluor 568 and anti-chicken
IgG conjugated with Alexa Fluor 488 (Molecular Probes), both diluted 1:200. Nuclei were stained with 4,6-diamidino2-phenylindole (DAPI), and coverslips were mounted on glass slides (VectaShield Hard Set mounting medium with DAPI H1500, Vector Laboratories, Burlingame, CA, USA). Images were analyzed using a confocal microscope Fluoview 1000 (Olympus).

For quantification of insulin production, images of pancreas sections were digitally captured in $200 \times$ magnification using a digital color camera adapted to an AX70 microscope with an epifluorescence system plus grid to enhance the fluorescence resolution (Optigrid, structured light imaging system; Thales Optem Inc., Olympus). Ten random fields were captured per pancreas and analyzed using Image Pro Plus v. 7.0 (Media Cybernetics, Rockville, MD, USA), which automates the analysis by segmentation, converting all immunolabeled elements that fall within a threshold range into red pixels and the rest of the image into yellow pixels. The same threshold range that defined positivity was used in all images analyzed. The software then calculates the percentage of red and yellow, allowing for the comparison of the pixel values between the groups, defined as the percentage of stained area.

\section{Real-Time Polymerase Chain Reaction ( $q P C R$ )}

Total RNA was isolated from kidney samples with TRIzol reagent (Invitrogen), and concentration was determined by photometric measurement. High-Capacity cDNA Reverse Transcription Kit (Applied Biosystems, Foster City, CA, USA) was used to synthesize cDNA of $1 \mu \mathrm{g}$ RNA following the manufacturer's recommendations. RT-PCR assays were performed to detect the expression levels of eGFP. qRT-PCR amplification mixtures 
contained 20 ng template cDNA, Taqman Master Mix $(10 \mu \mathrm{l})($ Applied Biosystems), and probes for eGFP (Assay by Design; Applied Biosystems) in a final volume of $20 \mu \mathrm{l}$. All reactions were run in duplicate on an ABI7500 Sequence Detection System (Applied Biosystems) under standard thermal cycling conditions. The mean $\mathrm{Ct}$ (cycle threshold) values from duplicate measurements were used to calculate expression of the target gene, with normalization to an internal control [glyceraldehyde 3-phosphate dehydrogenase (GAPDH) Mm 9999915_g1] using the $2^{-\mathrm{DCt}}$ formula. Experiments with coefficients of variation greater than $5 \%$ were excluded. A no-template control (NTC) and no-reverse transcription controls (No-RT) were also included.

\section{Statistical Analysis}

Parametric data were analyzed using one-way ANOVA with Tukey's post hoc test or repeated measures two-way ANOVA with Bonferroni's post hoc test, when appropriate. Nonparametric data were analyzed using the MannWhitney test. All data were analyzed using the Prism 5.01 computer software (GraphPad, San Diego, CA, USA). Statistical differences were considered to be significant at $p<0.05$.

\section{RESULTS}

\section{Establishment of Diabetes Model}

STZ was used to produce hyperglycemia in C57B1/6 mice. Several STZ concentrations (40, 80, and $120 \mathrm{mg} /$ $\mathrm{kg}$ ) were used in the standardization of this experimental model (data not shown), but only the concentration of $80 \mathrm{mg} / \mathrm{kg}$ administrated over three consecutive days was able to induce hyperglycemia in the animals. Ten days after the first STZ dose, mice presented about 2.6 times more blood glucose compared with nontreated mice (Fig. 2A). A morphologic assessment of hematoxylin and eosin-stained pancreas sections showed insulitis (Fig. 2C) and reduction of insulin levels as observed by immunofluorescence (Fig. 2E). Moreover, STZ-treated mice presented deposition of glycogen in the tubules (Armanni-Ebstein change), a renal lesion characteristically associated with diabetes (Fig. 2G).

\section{Glucose Levels and Renal Function}

Mice treated with STZ became apathic and presented polyuria when compared to mice that received citrate buffer only. After transplantation, the body weight variation in diabetic mice that received mDPSCs was similar to that observed in nondiabetic mice during all of the experimental period. In contrast, diabetic mice treated with saline exhibited a significant body weight loss (Fig. 3). Moreover, 21 days after beginning the experiment, blood glucose levels were reduced in hyperglycemic mice transplanted with mDPSCs when compared to those of saline-treated mice (Fig. 4).

Correlating with the improvement of glucose levels, diabetic mice transplanted with mDPSCs presented a higher number of pancreatic islets when compared with nontransplanted diabetic mice (Fig. 5A). Immunostaining for insulin confirmed the increase in insulinproducing area in the pancreas of mDPSC-transplanted mice (Fig. 5B).

To evaluate the renal function, the urine levels of glucose, protein, urea, and creatinine were measured. Diabetic mice treated with mDPSCs showed significantly reduced glucose and protein levels (Fig. 6A, B) and higher urea (Fig. 6C) when compared to saline-treated diabetic mice. Creatinine levels were also higher in diabetic mice treated with mDPSCs compared with salinetreated diabetic mice, although the differences were not statistically significant $(p=0.0582)$ (Fig. 6D). Moreover, diabetic mice did not develop morphologic alterations in glomeruli or vascular areas, probably due to the short time of disease (30 days). However, we observed the loss of the epithelial brush border and proximal tubule dilatation in saline-treated diabetic mice, which is indicative of acute renal lesion. In contrast, these alterations were not observed in mice transplanted with mDPSCs, which had renal parenchyma similar to those of nondiabetic mice. The Armanni-Ebstein change, a deposition of glycogen in the tubules, was more severe in saline-treated than in mDPSC-treated diabetic mice (Table 1). No $\mathrm{GFP}^{+}$cells were found in the kidneys of mDPSC-transplanted mice, by either immunofluorescence or PCR analyses (data not shown).

\section{Effect of mDPSC Transplantation on the STZ-Induced Painful Neuropathy}

Sensory testing results from tail flick assay are shown in Figure 7. Baseline response latencies before treatment were similar for all groups. Four days after STZ or saline treatment, the response latencies were significantly lower $(p<0.001)$ for the diabetic groups relative to the salinetreated group, indicating the development of a marked thermal hyperalgesia. Three days after mDPSC transplantation, diabetic mice treated with mDPSCs exhibited nociceptive thresholds similar to the nondiabetic mice. This effect was maintained throughout the testing period. We observed hyperalgesia $(p<0.001)$ in diabetic mice from 1 week following the induction of diabetes that progressed to hypoalgesia $(p<0.05)$. However, neither hyperalgesia nor hypoalgesia were observed in diabetic mice after the mDPSC transplantation.

\section{Pancreatic Engraftment of mDPSCs}

To examine whether mDPSCs migrate to and engraft in the damaged pancreas after STZ treatment, pancreas 
A
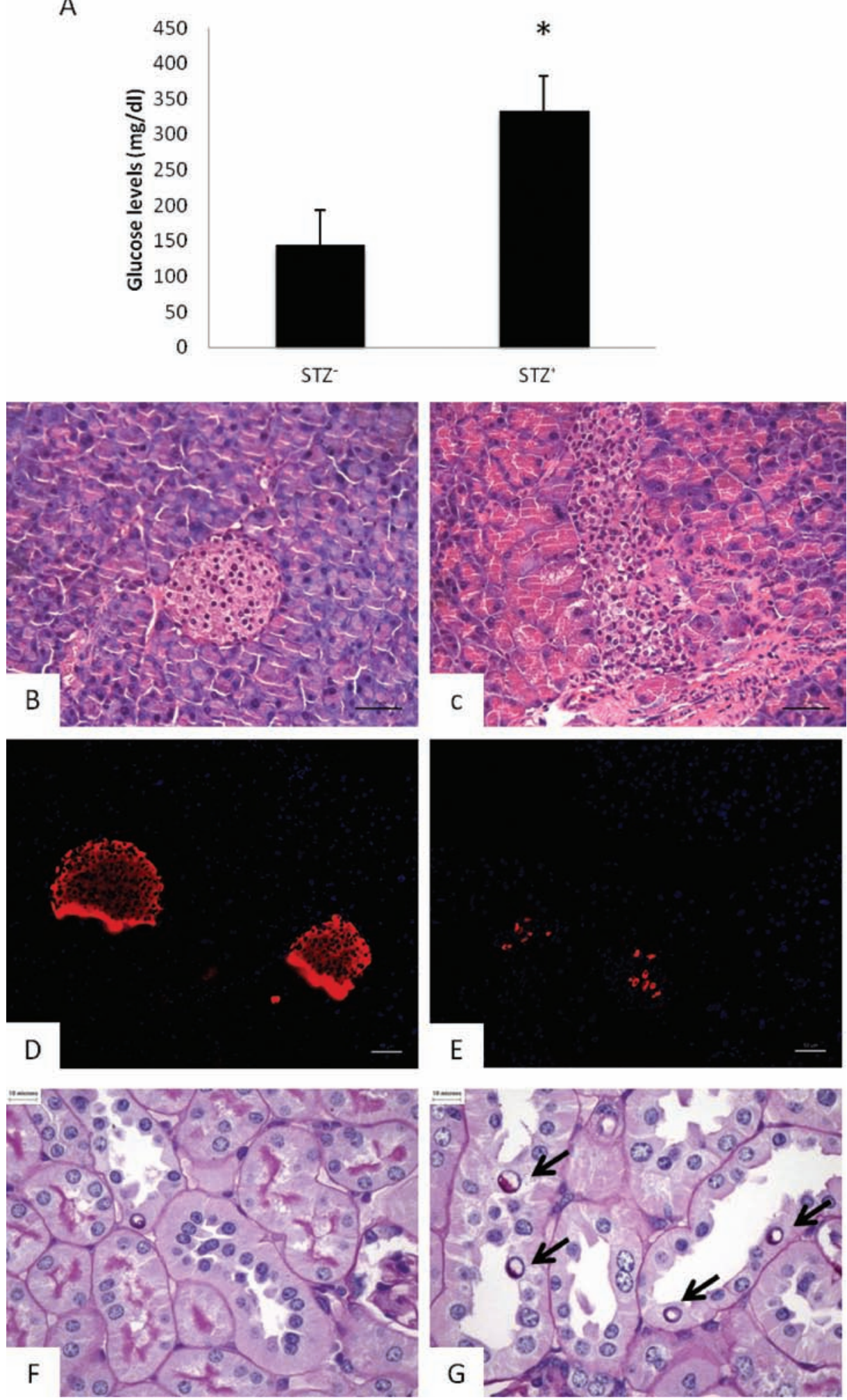

Figure 2. Establishment of diabetes model induced by streptozotocin administration. (A) Increased blood glucose levels correlated with the presence of $(C)$ insulitis in pancreas sections stained with hematoxylin and eosin $(H \& E)$ and $(E)$ with the decreased number of insulin-expressing cells (red) analyzed by immunofluorescence in STZ-treated mice, in contrast to untreated C57Bl/6 mice (B, D). Histological examination of kidney sections by light microscopy. (F) Normal kidney. (G) Glycogen deposition was observed in diabetic mice (arrows). Scale bars: $50 \mu \mathrm{m}$. 


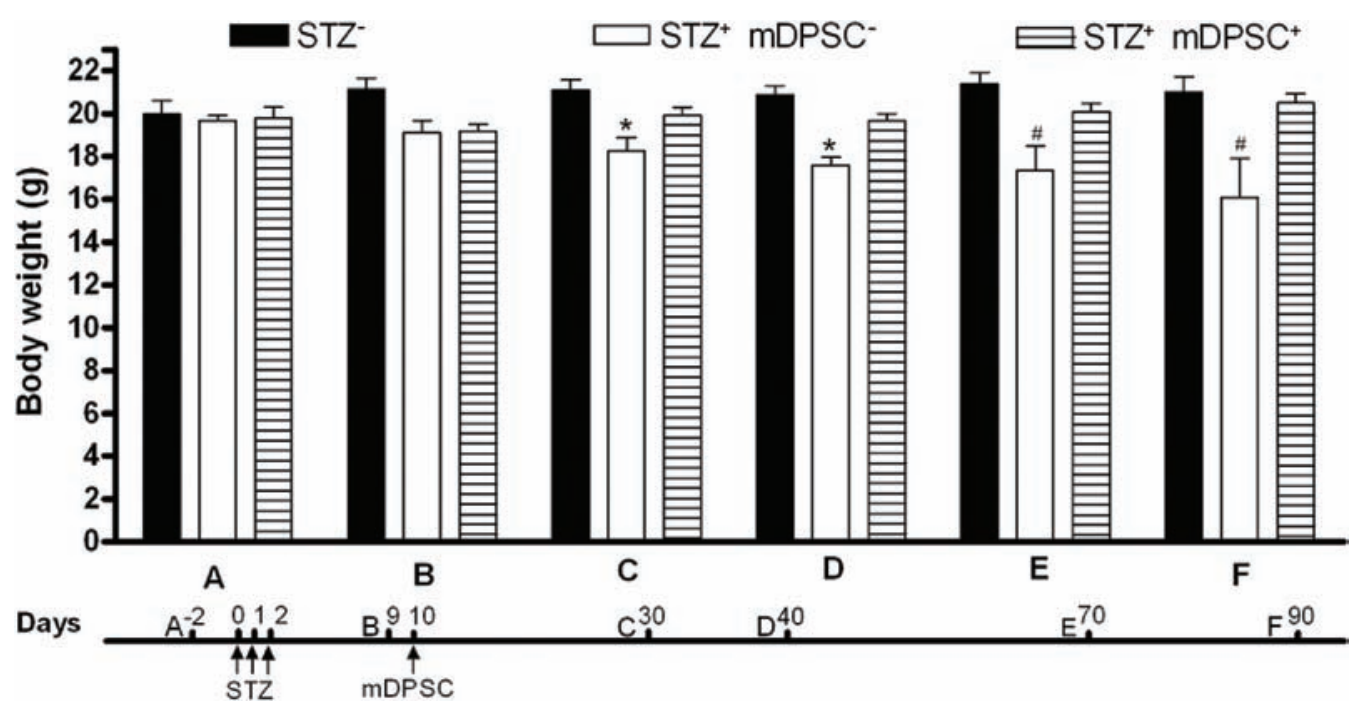

Figure 3. Body weight variation in STZ-diabetic mice after mDPSC transplantation. Body weight was evaluated before (A) and 1 week after (B) streptozotocin administration. Groups of mice treated with streptozotocin and treated with mDPSCs $\left(\mathrm{STZ}^{+} \mathrm{mDPSC}^{+}\right)$or saline $\left(\mathrm{STZ}^{+} \mathrm{mDPSC}^{-}\right)$and nondiabetic mice (STZ-) are represented in the figure. The body weight is shown only for 20 (C), 30 (D), 60 (E), and $80(\mathrm{~F})$ days after mDPSC transplantation (on day 10). Data are expressed as mean $\pm \operatorname{SEM}(n=6)$. $* p<0.05$ compared to the control group (STZ); $\# p<0.05$ compared with other groups; tested by two-way ANOVA with Bonferroni's post hoc.

sections were immunostained with anti-insulin antibody and analyzed by confocal microscopy. Insulin-producing cells in the pancreatic islets were observed, some of them coexpressing GFP (Fig. 8). Some $\mathrm{GFP}^{+}$, insulin-negative cells were found surrounding the islets (Fig. 8D).

\section{DISCUSSION}

In the present study, using an experimental model of diabetes mellitus, we demonstrated that the administration of mDPSCs improves pancreatic damage, renal function, and diabetic neuropathic pain.
We used a model of diabetes mellitus type 1 induced by STZ in mice to assess whether mDPSCs can home and repair injured tissue in vivo because insulitis, hyperglycemia, and neuropathy are well documented in this model, mimicking human diabetes $(8,32)$. In our study, thermal hyperalgesia, severe hyperglycemia, and renal dysfunction were observed 10 days after the first STZ administration in C57BL/6 mice, and no spontaneous recovery was observed. Previous studies have shown reduction, but not complete reversion, of hyperglycemia after transplantation with a single dose of bone marrow-derived stem or

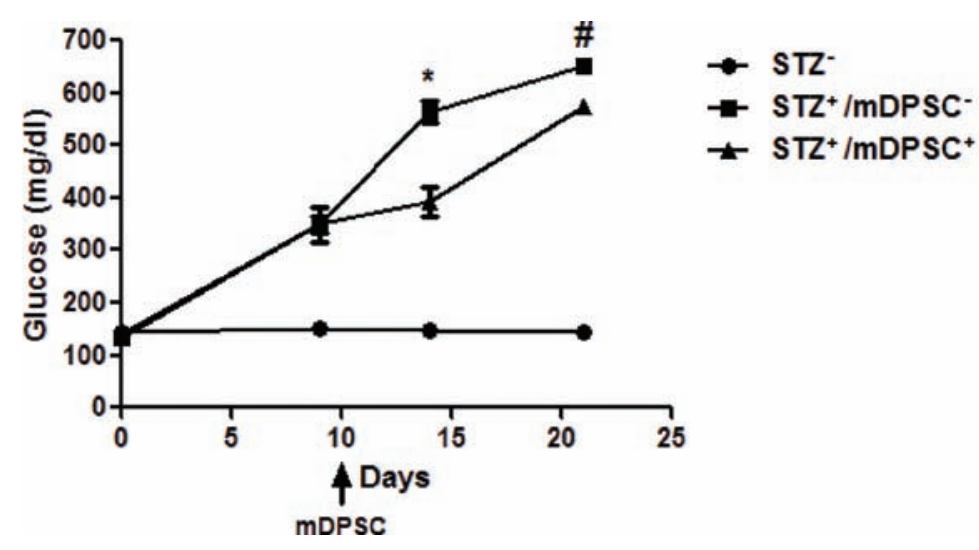

Figure 4. Transplantation of mDPSCs reduces blood glucose levels in STZ-diabetic mice. Comparison of blood glucose levels in STZ-treated mice injected with saline or transplanted with $10^{6}$ cells $(n=6 /$ group $)$. Data are expressed as mean \pm SEM. $* p<0.001$ and $\# p<0.05$ for $\mathrm{STZ}^{+} \mathrm{mDPSC}^{+}$versus $\mathrm{STZ}^{+} \mathrm{mDPSC}^{-}$group, using two-way ANOVA with Bonferroni's post hoc. 
A

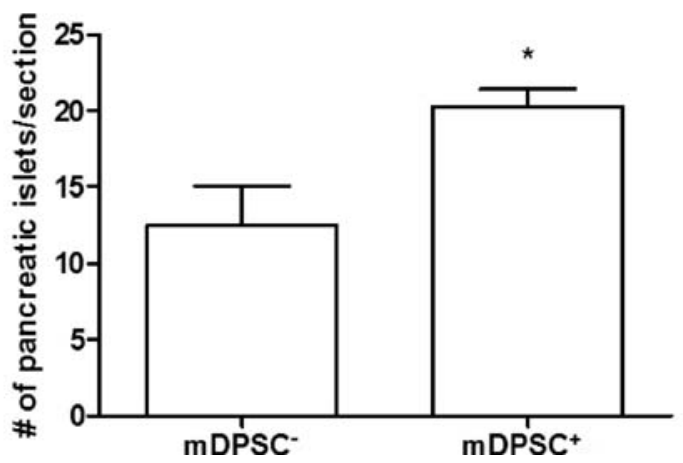

B

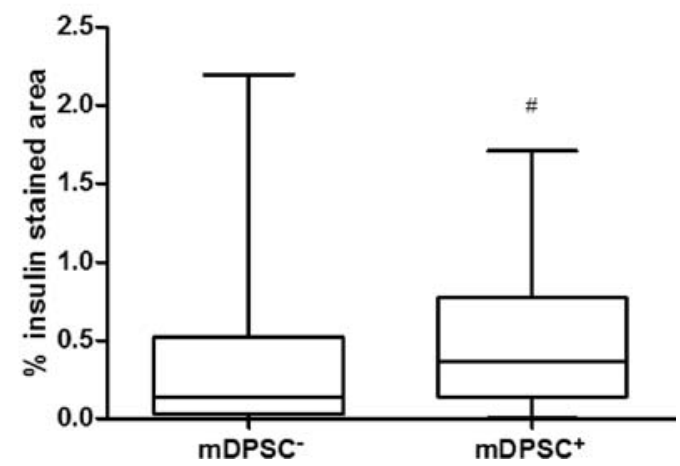

Figure 5. Quantification of pancreatic islets and insulin production after mDPSC transplantation. The number of islets was determined in H\&E-stained pancreatic sections of STZ-treated mice transplanted or not with mDPSCs (A). Quantification of insulin-producing area by immunofluorescence analysis (B). ${ }^{*} p<0.05$, tested by one-way ANOVA, and $\# p<0.05$, tested by Mann-Whitney’s test.
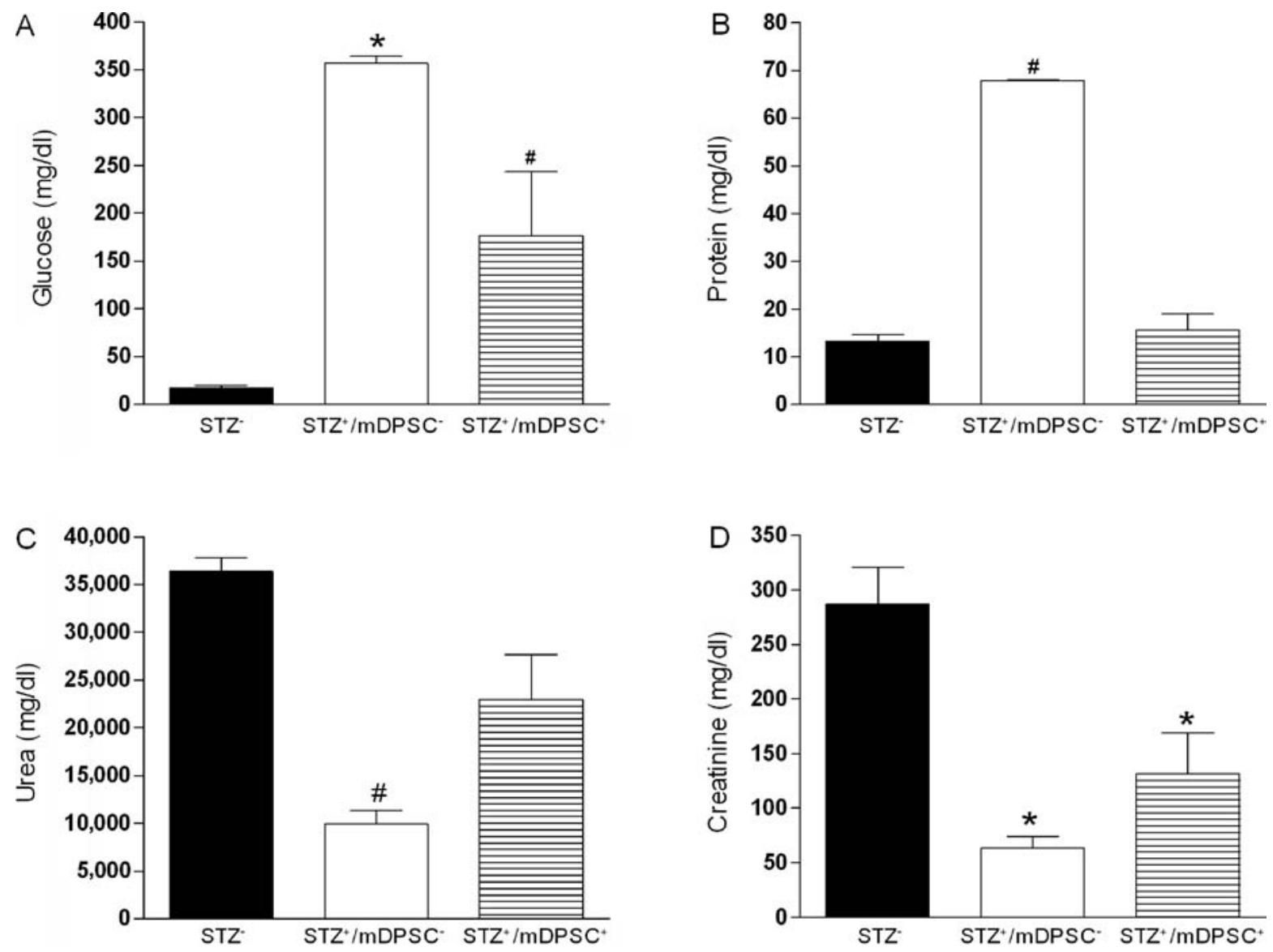

Figure 6. Improvement of the renal function in transplanted mice with mDPSCs. Thirty days after the mDPSC transplant, urine was collected and the levels of glucose (A), protein (B), urea (C), and creatinine (D) were measured. Data are expressed as mean \pm SEM $(n=6){ }^{*} p<0.05$ compared with the control group (STZ-); $\# p<0.05$ compared to the other groups; tested by one-way ANOVA with Tukey's post hoc. 
Table 1. Morphologic Alterations in the Kidney After Diabetes Induction and mDPSC Transplantation

\begin{tabular}{lcccc}
\hline Experimental Group & $\begin{array}{c}\text { Glomerular and } \\
\text { Vascular Changes }\end{array}$ & $\begin{array}{c}\text { Deposition of Glycogen } \\
\text { in the Tubules }\end{array}$ & $\begin{array}{c}\text { Loss of } \\
\text { Brush Border }\end{array}$ & $\begin{array}{c}\text { Tubular } \\
\text { Dilatation }\end{array}$ \\
\hline Nondiabetic mice & - & - & - & - \\
Diabetic nontransplanted mice & - & $+++/++$ & ++++ & $++/++$ \\
Diabetic mice transplanted with mDPSC & - & $+/+++$ & - & - \\
\hline
\end{tabular}

$(-)$, absent; (+), present in less than $25 \%$ of the analyzed fields; $(++)$, present in $50 \% ;(+++)$, present in 100\%; mDPSC, mouse dental pulp-derived stem cell.

endothelial cells in diabetic mice $(8,11)$. Similarly, in the present study, we observed that a single mDPSC administration into diabetic mice resulted in reduction of glucose levels. However, hyperglycemia increased gradually with time, even in mDPSC-treated mice, suggesting the need for additional doses to sustain the effects. Thus, the number of cells and doses to achieve a better therapeutic effect is a parameter still to be evaluated.

Moreover, we observed GFP and insulin coexpression in the pancreatic islets. Cells only expressing GFP were found less frequently in a peri-islet distribution. These data correlate with reports showing that stem cells obtained from other sources, such as bone marrow, can engraft and transdifferentiate into a pancreatic endocrine $\beta$-cell phenotype in vivo (7) or surround pancreatic islets and ducts and produce factors that stimulate resident cells of the pancreas in recipient mice in vivo (12). In contrast, Lechner et al. (21) did not find a significant engraftment of bone marrow-derived $\beta$-cells in the pancreatic islet after partial pancreatectomy or STZ administration. Differences in the model and mouse strain used, STZ dosage, route of administration, and the number and source of transplanted cells may therefore influence the fate of the cells.
We also observed improvement of renal function in mice transplanted with mDPSCs by evaluation of the biochemical parameters. Ezquer et al. (8) suggested that the therapeutic effects of mesenchymal stem cells in the kidney include the modulation of the inflammatory process and neovascularization after kidney damage. Microalbuminuria reversion and the absence of renal histopathological alterations were observed in diabetic mice transplanted with mesenchymal stem cells obtained from bone marrow (8). In addition, Sca- $1^{+}$cells isolated from adult mouse bone marrow are mobilized into the circulation by transient renal ischemia, specifically home to injured regions and differentiate into renal tubular epithelial cells (15). In our model, $\mathrm{GFP}^{+}$mDPSCs were not observed in the kidney of transplanted diabetic mice by immunofluorescence analyses $48 \mathrm{~h}$ and 30 days after transplantation (data not shown). Therefore, we suggest that improvements in kidney function are a consequence of lower glucose levels promoted by mDPSC transplantation.

It has been suggested that diabetic neuropathy is causally related to the reduction of blood flow and conduction velocity in the nerve, impaired angiogenesis, and deficient growth factors $(1,3,17,20,25)$. A recent study demonstrated

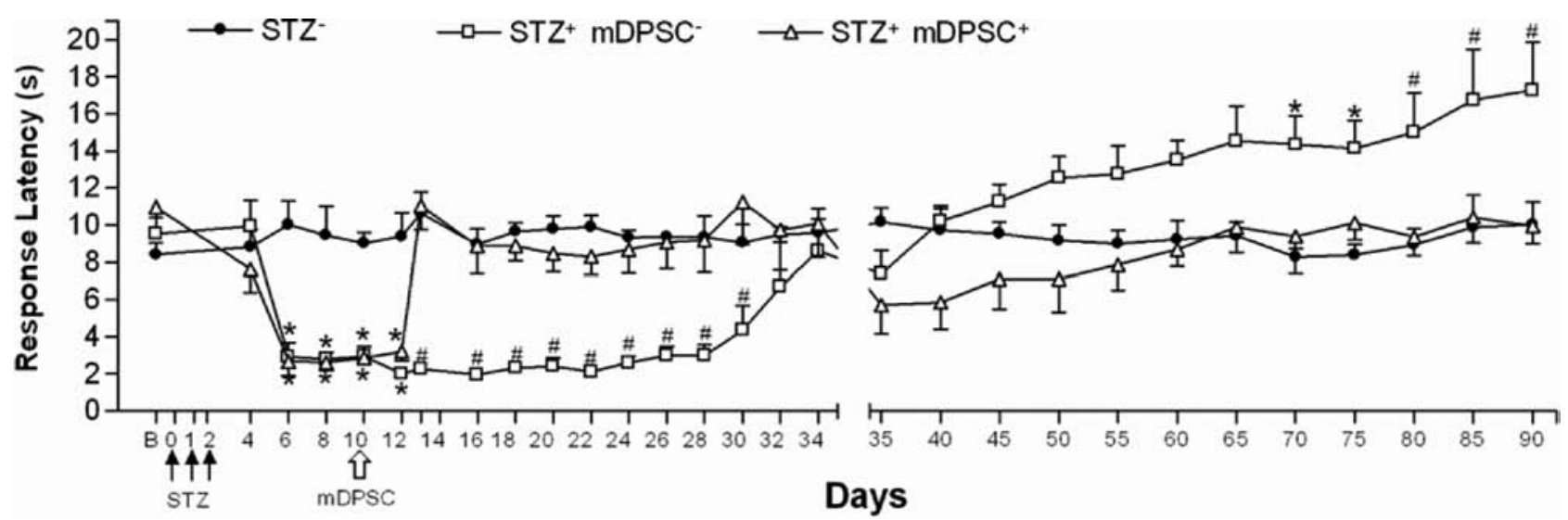

Figure 7. Prolonged antinociceptive effect of a single transplantation of mDPSCs in STZ-diabetic mice. Baseline response latencies (B) were performed before the treatments for all groups. The tail flick test was carried out daily during all of the experimental period, but the figure shows only data from selected days. Data are expressed as mean $\pm \operatorname{SEM}(n=6)$. ${ }^{*} p<0.01$ compared with the control group $\left(\mathrm{STZ}^{-}\right)$; $\# p<0.01$ compared to the other groups; tested by two-way ANOVA with Bonferroni's post hoc. 

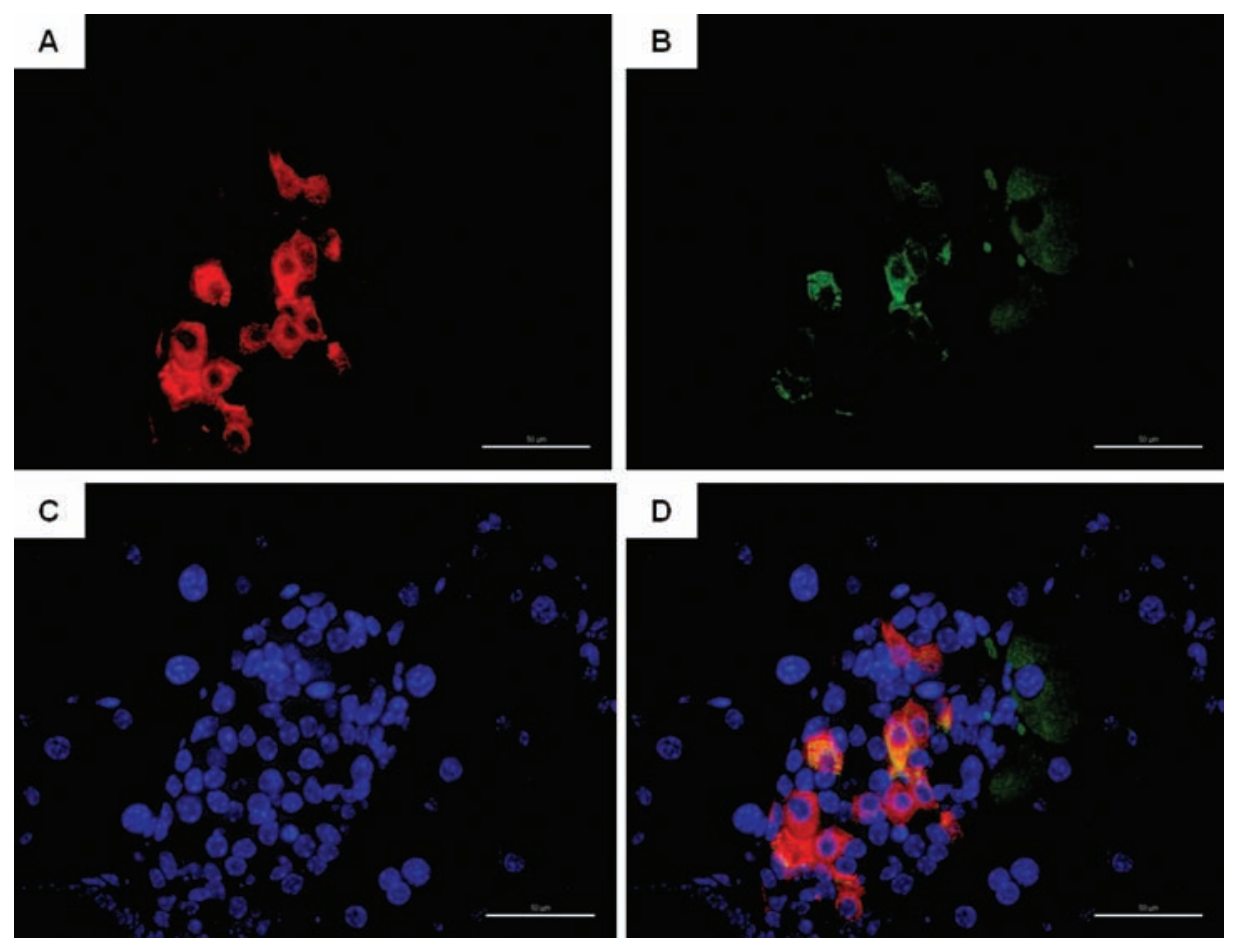

Figure 8. Transplanted mDPSCs transdifferentiate into insulin-producing cells and surround STZ-damaged pancreas. Pancreas sections of mDPSC-transplanted mice were analyzed 30 days after the first STZ administration and subjected to staining with anti-insulin antibody (red; A). Green fluorescent protein (GFP)+ cells were detected (green; B). Nuclei were stained with 4,6-diamidino-2-phenylindole (DAPI) (blue; C). Merged image is shown in (D). Scale bars: $50 \mu \mathrm{m}$.

that the transplantation of bone marrow-derived endothelial progenitor cells in STZ-induced diabetic mice improves the nerve conduction velocity, blood flow, and capillary density in the sciatic nerve (14). In addition, the authors observed increased angiogenic and neurotrophic factors in sciatic nerves of transplanted mice. In the present study, we demonstrated, for the first time, that transplantation of dental pulp stem cells produces a powerful and longlasting antinociceptive effect in mice with diabetic neuropathic pain. Interestingly, the observed antinociception was not only rapid but also irreversible, an effect that is hardly reached by analgesics clinically used. The mechanism underlying the effectiveness of mDPSC transplantation for diabetic neuropathic pain is unknown; however, it may result from secretion of anti-inflammatory, angiogenic, and neurotrophic factors by transplanted cells.

In conclusion, our study supports the concept that mDPSCs could reverse frequent complications of diabetes, such as pancreatic $\beta$-cell destruction, renal damage, and neuropathic pain, and suggest that dental pulp is an innovative source of insulin-producing cells and could represent an option for the control of intractable diabetic neuropathic pain.
ACKNOWLEDGMENTS: This work was supported by CNPq, FAPESB, FINEP, and FIOCRUZ. The authors declare no conflicts of interest.

\section{REFERENCES}

1. Andriambeloson, E.; Baillet, C.; Vitte, P. A.; Garotta, G.; Dreano, M.; Callizot, N. Interleukin-6 attenuates the development of experimental diabetes-related neuropathy. Neuropathology 26:32-42; 2006.

2. Bolzán, A. D.; Bianchi, M. S. Genotoxicity of streptozotocin. Mutat. Res. 512:121-134; 2002.

3. Cameron, N. E.; Cotter, M. A.; Low, P. A. Nerve blood flow in early experimental diabetes in rats: Relation to conduction deficits. Am. J. Physiol. 261:1-8; 1991.

4. Choi, S.; Choia, K.; Yoona, H.; Shina J.; Kima, J.; Parke, W.; Hanf, D.; Kimf, S.; Ahnb, C.; Kimb, J.; Hwanga, E.; Chaa, C.; Szotg, G. L.; Yoonh, K.; Park, C. IL-6 protects pancreatic islet beta cells from pro-inflammatory cytokines induced cell death and functional impairment in vitro and in vivo Transpl. Immunol. 13:43-53; 2004.

5. Cnop, M.; Welsh, N.; Jonas, J. C.; Jorns, A.; Lenzen, S.; Eizirik, D. L. Mechanisms of pancreatic $\beta$-cell death in type 1 and type 2 diabetes. Diabetes 54(Suppl 2):S97S107; 2005.

6. D'Amour, F. E.; Smith, D. L. A method for determining loss of pain sensation. J. Pharmacol. Exp. Ther. 72:74-78; 1941. 
7. Di Gioacchino, G.; Di Campli, C.; Zocco, M. A.; Piscaglia, A. C.; Novi, M.; Santoro, M.; Santoliquido, A.; Flore, R.; Tondi, P.; Pola, P.; Gasbarrini, G.; Gasbarrini, A. Transdifferentiation of stem cells in pancreatic cells: State of the art. Transplant. Proc. 37:2662-2673; 2005.

8. Ezquer, E. E.; Ezquer, M. E.; Parrau, D. B.; Carpio, D.; Yanez, A. F.; Conget, P. A. Systemic administration of multipotent mesenchymal stromal stem cells reverts hyperglycemia and prevents nephropathy in type 1 diabetic mice. Biol. Blood Marrow Transplant. 14:631-640; 2008.

9. Gillespie, K. M. Type 1 diabetes: Pathogenesis and prevention. Can. Med. Assoc. J. 175:165-170; 2006.

10. Guimarães, E. T.; Cruz, G. S.; Jesus, A. A.; Carvalho, A. F. L.; Rogatto, S. R.; Pereira, L. V.; Ribeiro-dos-Santos, R.; Soares, M. B. P. Mesenchymal and embryonic characteristics of stem cells obtained from mouse dental pulp. Arch. Oral Biol. 56:1247-1255; 2011.

11. Hasegawa, Y.; Ogihara, T.; Yamada, T.; Ishigaki, Y.; Imai, J.; Uno, K.; Gao, J.; Kaneko, K.; Ishiara, H.; Sasano, H.; Nakaushi, H.; Oka, Y.; Katagiri, H. Bone marrow transplantation promotes $\beta$-cell regeneration after acute injury through BM cell mobilization. Endocrinology 146:20062015; 2006.

12. Hess, D.; Li, L.; Martin, M.; Sakano, S.; Hill, D.; Strutt, B.; Thyssen, S.; Gray, D. A.; Bhatia, M. Bone marrow-derived stem cells initiate pancreatic regeneration. Nat. Biotechnol. 21:763-770; 2003.

13. Huang, A. H.; Snyder, B. R.; Cheng, P. H.; Chan, A. W. Putative dental pulp-derived stem/stromal cells promote proliferation and differentiation of endogenous neural cells in the hippocampus of mice. Stem Cells 26:2654-2663; 2008.

14. Jeong, J. O.; Kim, M. O.; Kim, H.; Lee, M. Y.; Kim, S. W.; Li, M.; Lee, J. U.; Lee, J.; Choi, Y. J.; Cho, H. J.; Lee, N.; Silver, M.; Wecker, A.; Kim, D. W.; Yoon, Y. S. Dual angiogenic and neurotrophic effects of bone marrow-derived endothelial progenitor cells on diabetic neuropathy. Circulation. 119:699-708; 2009.

15. Kale, S.; Karihaloo, A.; Clark, P. R.; Kashgarian, M.; Krause, D. S.; Cantley, L. G. Bone marrow stem cells contribute to repair of the schemically injured renal tubule. J. Clin. Invest. 112:42-49; 2003.

16. Kerkis, I.; Kerkis, A.; Dozortsev, D.; Stukart-Parsons, G. C.; Gomes, S. M.; Pereira, L. V. Isolation and characterization of a population of immature dental pulp stem cells expressing OCT- 4 and other embryonic stem cell markers. Cells Tissues Organs 184:105-116; 2006.

17. Kerr, D. A.; Lladó, J.; Shamblott, M. J.; Maragakis, N. J.; Irani, D. N.; Crawford, T. O.; Krishnan, C.; Dike, S.; Gearhart, J. D.; Rothstein, J. D. Human embryonic germ cell derivatives facilitate motor recovery of rats with diffuse motor neuron injury. J. Neurosci. 23:5131-5140; 2003.

18. King, J. C. Therapeutic options for neurophatic pain. J. Trauma 62:95-105; 2007.
19. Klass, M.; Gavrikov, V.; Drury, D.; Stewart, B.; Hunter, S.; Denson, D. D.; Hord, A.; Csete, M. Intravenous mononuclear marrow cells reverse neuropathic pain from experimental mononeuropathy. Anesth. Analg. 104:944-948; 2007.

20. Kusano, K. F.; Allendoerfer, K. L.; Munger, W.; Pola, R.; Bosch-Marce, M.; Kirchmair, R.; Yoon, Y. S.; Curry, C.; Silver, M.; Kearney, M.; Asahara, T.; Losordo, D. W. Sonic hedgehog induces arteriogenesis in diabetic vasa nervorum and restores function in diabetic neuropathy. Arterioscler. Thromb. Vasc. Biol. 24:2102-2107; 2004.

21. Lechner, A.; Yang, Y. G.; Blacken, R. A.; Wang, L.; Nolan, A. L.; Habener, J. F. No evidence for significant transdifferentiation of bone marrow into pancreatic $\beta$-cells in vivo. Diabetes 53:616-623; 2004.

22. Lee, R. H.; Seo, M. J.; Reger, R. L.; Spees, J. L.; Pulin, A. A.; Olson, S. D.; Prockop, D. J. Multipotent stromal cells from human marrow home to and promote repair of pancreatic islets and renal glomeruli in diabetic NOD/Scid mice. Proc. Natl. Acad. Sci. USA 106:17438-17443; 2006.

23. Leinninger, G. M.; Vincent, A. M.; Feldman, E. L. The role of growth factors in diabetic peripheral neuropathy. J. Peripher. Nerv. Syst. 9:26-53; 2004.

24. Liu, S.; Qu, Y.; Stewart, T. J.; Howard, M. J.; Chakrabortty, S.; Holekamp, T. F.; McDonald, J. W. Embryonic stem cells differentiate into oligodendrocytes and myelinate in culture and after spinal cord transplantation. Proc. Natl. Acad. Sci. USA 97:6126-6131; 2000.

25. Myckatyn, T. M.; Brenner, M.; Mackinnon, S. E.; Chao, C. K.; Hunter, D. A.; Hussussian, C. J. Effects of external beam radiation in the rat tibial nerve after crush, transection and repair, or nerve isograft paradigms. Laryngoscope 114:931-938; 2004.

26. Notkins, A. L.; Lernmark, A. Autoimmune type 1 diabetes: Resolved and unresolved issues. J. Clin. Invest. 108:12471252; 2001.

27. Oh, S. H.; Muzzonigro, T. M.; Bae, S. H; LaPlante, J. M.; Hatch, H. M.; Petersen, B. E. Adult bone marrow-derived cells transdifferentiating into insulin-producing cells for the treatment of type 1 diabetes. Lab. Invest. 84:607-617; 2004.

28. Shoelson, S. E.; Lee, J.; Goldfine, A. B. Inflammation and insulin resistance. J. Clin. Invest. 116:1793-1801; 2006.

29. Szkudelski, T. The mechanism of alloxan and streptozotocin action in B-cells of the rat pancreas. Physiol. Res. 50:536-546; 2001.

30. Thomas, P. K. Diabetic neuropathy. Human and experimental. Drugs 32:36-42; 1986.

31. Voltarelli, J. C.; Couri, C. E. B.; Straciere, A. B. P. L.; Moraes, D. A.; Pieroni, F.; Coutinho, M.; Malmegrim, K. C. R.; Foss-Freitas, M. C.; Simões, B. P.; Foss, M. C.; Squiers, E.; Burt, R. K. Autologous nonmyeloablative hematopoietic stem cells transplantation in newly diagnosed type 1 Diabetes Mellitus. J. Am. Med. Assoc. 297:1568-1576; 2007. 